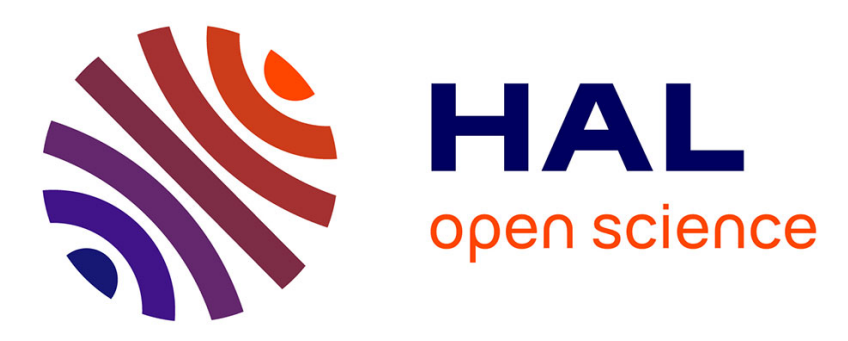

\title{
Abdominal morphometric data acquisition using depth sensors
}

\author{
Sylvia Piotin, Aassif Benassarou, Frédéric Blanchard, Olivier Nocent, Eric
}

Bertin

\section{- To cite this version:}

Sylvia Piotin, Aassif Benassarou, Frédéric Blanchard, Olivier Nocent, Eric Bertin. Abdominal morphometric data acquisition using depth sensors. 2013 IEEE 15th International Conference on e-Health Networking, Applications and Services (Healthcom 2013), Oct 2013, Lisbon, Portugal. 10.1109/HealthCom.2013.6720757 . hal-01697097

\section{HAL Id: hal-01697097 \\ https://hal.univ-reims.fr/hal-01697097}

Submitted on 5 Apr 2018

HAL is a multi-disciplinary open access archive for the deposit and dissemination of scientific research documents, whether they are published or not. The documents may come from teaching and research institutions in France or abroad, or from public or private research centers.
L'archive ouverte pluridisciplinaire HAL, est destinée au dépôt et à la diffusion de documents scientifiques de niveau recherche, publiés ou non, émanant des établissements d'enseignement et de recherche français ou étrangers, des laboratoires publics ou privés. 


\title{
Abdominal Morphometric Data Acquisition Using Depth Sensors
}

\author{
Sylvia Piotin*, Aassif Benassarou ${ }^{\dagger}$, Frédéric Blanchard ${ }^{\dagger}$, Olivier Nocent ${ }^{\dagger}$, Éric Bertin $^{\ddagger}$ \\ ${ }^{*}$ Centre Image \\ University of Reims, France \\ Email: sylvia.chalencon@univ-reims.fr \\ ${ }^{\dagger} \mathrm{CReSTIC}$ \\ University of Reims, France \\ $\ddagger$ Department of Endocrinology \\ Reims University Hospital, France \\ Email: ebertin@chu-reims.fr
}

\begin{abstract}
The treatment of eating disorders is now part of the priority actions of the public health policy. For several years, nutritionists have been using tools relying on new digital technologies, able to provide new diagnostic elements. In this paper, we propose a complete methodology to acquire, analyse morphological data and establish typologies with low cost consumer electronics devices. We use a Microsoft ${ }^{\circledR}$ Kinect $^{\mathrm{TM}}$ like peripheral to capture abdominal measurements. For each individual, we calculate two profiles in the sagittal and transverse planes respectively. The extracted quantitative information is then analyzed to build typologies of abdominal morphology.
\end{abstract}

\section{INTRODUCTION}

Nutrition and eating disorders have become a national public health priority. In 2001, France launched the National Health and Nutrition Programme (PNNS ${ }^{1}$ ) which aims to improve the health status of the population by acting on one of its major determinants: nutrition. At the regional level, ChampagneArdenne particularly suffers from obesity. According to the 2012 study ObEpi [1], the Champagne Ardenne region has experienced the highest increase in prevalence of obesity between 1997 and $2012(+145,9 \%)$ and became the second region most affected behind the Nord Pas-de-Calais region, with an obesity rate of $20,9 \%$ (the national average is $15 \%$ ). Within this context, the study of eating behaviors is an important issue for the understanding and prevention of disorders and diseases related to food. Building typologies of patients with eating disorders would help to better understand these diseases, thus allowing their prevention.

We plan to develop a new acquisition pipeline in order to identify new objective variables based on morphological parameters like abdominal diameter, body surface area, etc. While a recent report by the French Academy of Medicine on unnecessarily prescribed tests ${ }^{2}$ highlights the generalized use of heavy and expensive imaging, the novelty of our

\footnotetext{
${ }^{1}$ http://www.mangerbouger.fr/pnns/
}

${ }^{2}$ http://www.academie-medecine.fr

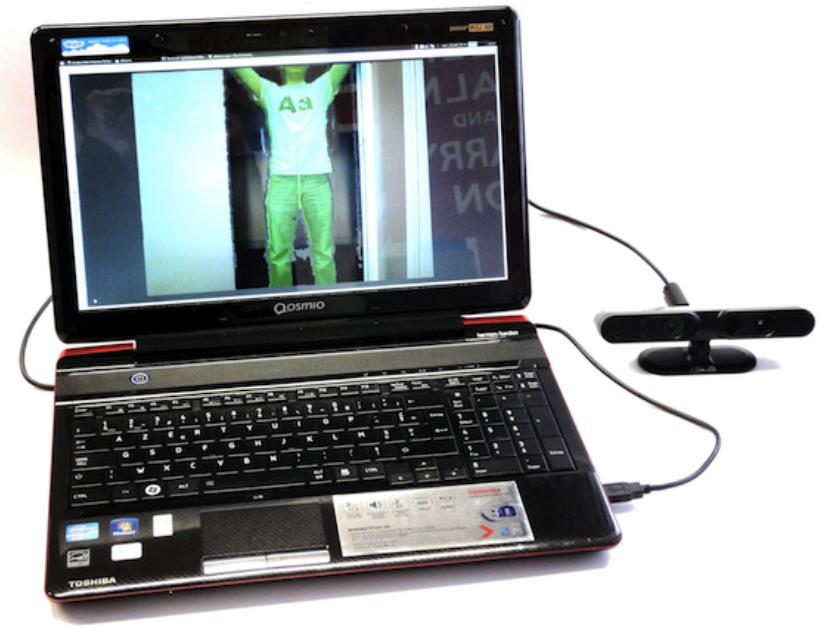

Figure 1. Presentation of our mobile system

approach lies in the use of a consumer electronics device (the Microsoft ${ }^{\circledR}$ Kinect $^{\mathrm{TM}}$ sensor was initially dedicated to the Microsoft ${ }^{\circledR}$ Xbox $360^{\mathrm{TM}}$ game console). This device has the advantage of being inexpensive, lightweight and less intrusive than conventional medical equipments. Even if these devices have been used in eHealth projects, their use has often been limited to the adaptation of successful video games to the medical environment: physical training programs to action against obesity [2], rehabilitation programs [3]. Within our project, the device is used as a measurement tool to collect morphological information in order to enrich or to confront the information extracted from surveys filled in by patients. Beyond its cost, this device can also be easily deployed in patient's homes or in medical practitioners offices, allowing monitoring on a regular basis (Figure 1)

This paper presents the acquisition and analysis 
methodology that we have implemented. The results presented were obtained on a sample of seventeen healthy patients without any medical context. The main objective was to establish a proof of concept.

After an overview of the uses of Kinect ${ }^{\mathrm{TM}}$ like sensors in a medical context, we present our abdominal morphology acquisition system. In the next section, the computation of quantitative indicators from raw data is exposed. Finally, we propose a first statistical analysis before concluding and presenting our future works.

\section{RELATED WORK}

The Microsoft ${ }^{\circledR}$ Kinect $^{\mathrm{TM}}$ peripheral, as well as its recent competitor ASUS ${ }^{\circledR}$ Xtion ${ }^{\mathrm{TM}}$, are made of an RGB camera, an IR emitter and an IR sensor. The latter is able to evaluate a depth map aligned with the video frame. Based on these two sources of data, it is possible to reconstruct people facing the device in 3D [4], [5].

the affordable cost of these new peripherals is probably the reason why they are inspiring so many projects. For instance, this technology is growingly involved in healthcare: apart from their use in fall risk assessment in elderly population [6], these cameras are also employed in motor rehabilitation programs [7], [8], or for the improvement of workplace ergonomics [9].

Not necessarily calling upon motion capture techniques, others use these cameras to quickly collect anthropometric data. Thanks to usual statistical tools such as principal component analysis, it is possible to extrapolate different morphological dimensions from a few measurements [10]. One can also deduce precisely the position of the center of mass of an individual if one combines a Kinect and a Wii Balance Board, popularized by the video game Wii Fit [11]. Finally, Velardo and Dugelay have developed an automated system capable of providing nutritional advice depending on the body mass index and basal metabolism rate calculated from parameters either measured or statistically induced from measurements [12].

\section{ACQUISITION ACCURACY}

Since the popularization of RGB-D devices (RGB + depth), many metrological studies have dealt with the quality of acquisition [13]: accuracy (difference between the measured and the real value) ranges from $5 \mathrm{~mm}$ to $15 \mathrm{~mm}$ at a distance of $1 \mathrm{~m}$, from $5 \mathrm{~mm}$ to $25 \mathrm{~mm}$ at a distance of $2 \mathrm{~m}$. Even if these lightweight tracking systems do not really compete with more cumbersome ones (such as Vicon's ${ }^{3}$ ), they can be a low cost alternative solution in many applications where high accuracy (less than $1 \mathrm{~mm}$ ) is not a matter of concern.

We also performed our own experiments. We scanned a wood panel with a $700 \mathrm{~mm}$ long diagonal at three different distances $(800 \mathrm{~mm}, 1600 \mathrm{~mm}$ and $2400 \mathrm{~mm})$. The values shown in tables I and II represent the mean value of ten consecutive measures. The improved accuracy observed, in

\footnotetext{
${ }^{3} \mathrm{http}: / /$ www.vicon.com
}

comparison with the aforementioned results, can be explained by the use of the mean value of several measurements. According to a framerate of 30 frames per second, a measure can be performed in a third of a second following our method. This is not really an issue since we are measuring static poses of patients.

\begin{tabular}{rrrr}
\hline Distance $(\mathrm{mm})$ & Measurement $(\mathrm{mm})$ & error $(\mathrm{mm})$ & relative error $(\%)$ \\
\hline 800 & 703 & 3 & 0.43 \\
1600 & 705 & 5 & 0.71 \\
2400 & 707 & 7 & 1.00 \\
\hline \multicolumn{4}{c}{ Table I } \\
DATA MEASURED WITH THE MICROSOFT ${ }^{\circledR}$ KINECT $^{\text {TM }}$ PERIPHERAL
\end{tabular}

\begin{tabular}{rrrr}
\hline Distance $(\mathrm{mm})$ & Measurement $(\mathrm{mm})$ & error $(\mathrm{mm})$ & relative error (\%) \\
\hline 800 & 695 & 5 & 0.71 \\
1600 & 693 & 7 & 1.00 \\
2400 & 693 & 7 & 1.00 \\
\hline \multicolumn{4}{c}{ Table II } \\
DATA MEASURED WITH THE ASUS ${ }^{\circledR}$ XTION $^{\text {TM }}$ PERIPHERAL
\end{tabular}

\section{MORPHOLOGIC DATA ACQUISITION}

In our study, we use the 3D reconstruction and pose detection capabilities of RGB-D devices to measure in real time several morphological characteristics of a patient (size, bust waist and hip measurements, shape of the abdomen, ... ). These data produced by the acquisition system can be compared to the patient's responses provided during the Stunkard's test: this test is to ask the patient about his perception (often subjective) of his morphology and ask him to lie within a range of silhouettes [14].

With the OpenNI library [15] and the NiTE middleware [16], we are able to identify the pixels corresponding to each user located in the sensor field. With this information, we reconstruct the visible body surface in 3D space. Since NiTE also allows us to track the skeleton of each individual, we can position planes on the abdomen: the sagittal plane and the transverse plane. By calculating the intersection between the surface and each plane we get a sagittal profile and a transverse profile (Figure 2). We can record these profiles in the patient's medical file to establish a follow-up. These profiles are also stored in an anonymized database to conduct a statistical analysis.

\section{PARAMETER EXTRACTION}

The previous step of acquisition provides two profiles from the intersection between the body surface and the sagittal and transverse planes. These profiles, composed of segments joining points from the reconstruction, are relatively noisy. A first step of smoothing using spline interpolation can adjust these geometric data and make them more "understandable" and exploitable (Figure 3).

After the first treatment we already have, for each individual, a first visual "signature" of the abdominal morphology (Figure 4). 


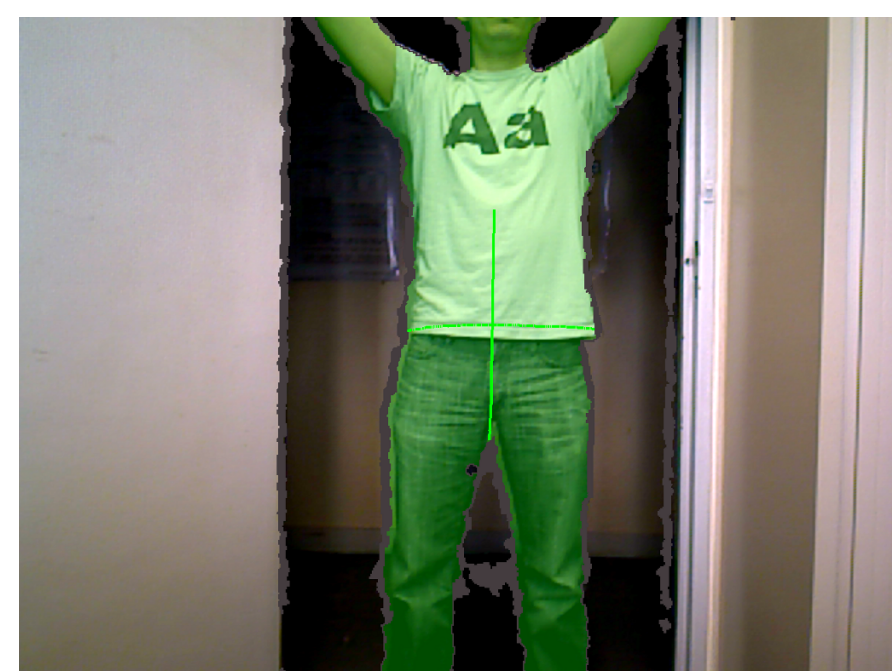

Figure 2. Acquisition of the sagittal and transverse profiles. The individual is highlighted and the two profiles are overprinted on his abdomen.

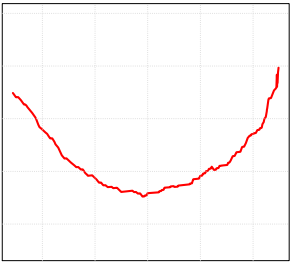

Captured profile

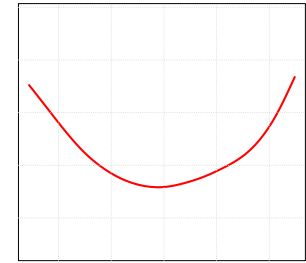

smoothed profile
Figure 3. Spline function smoot hing of the captured profiles

Patient 1
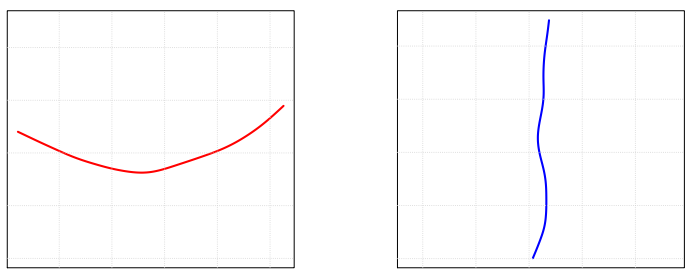

Patient 2
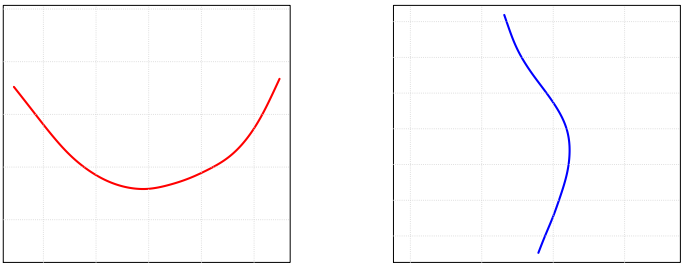

Figure 4. Examples of visual signatures of the abdominal morphology of two individuals. Left: transverse abdominal profile, right: sagittal abdominal profile.
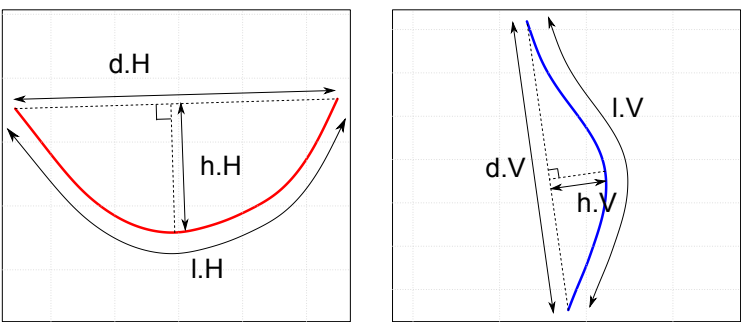

Figure 5. Examples of morphometric indicators calculated from the sagittal and transverse profiles

The interest of these visual signatures is to provide a simplified graphical representation to enable a fast and synthetic visualization. On the other hand, these visual descriptions facilitate description and interpretation of clusters when creating typologies by clustering. Finally, they have a major interest in monitoring the evolution of the patient by the doctor.

The profiles obtained during the acquisition are also used to extract features and more "conventional" measurements. It is possible, for example, from the smoothed cross-section, to calculate various lengths that are good estimations of the abdominal dimensions of the subject. In this study, we have limited ourselves, for example, to calculate the diameter $\left(d_{H}\right.$ and $\left.d_{V}\right)$, the height $\left(h_{H}\right.$ and $\left.h_{V}\right)$ and the length $\left(l_{H}\right.$ and $l_{V}$ ) of each profile (transverse and sagittal) (Figure 5). Other calculations of lengths or surfaces are possible [17], [18], [19].

The choice of these numerical descriptors of the abdominal morphology defines a parameter space in which subjects are represented. In this study, individuals who have lent to the experience are represented in a space of dimension 6 defined by the variables $d_{H}, d_{V}, h_{H}, h_{V}, l_{H}$ et $l_{V}$ (Table III).

\begin{tabular}{rrrrrrr}
\hline$i d$ & $d_{H}$ & $h_{H}$ & $l_{H}$ & $d_{V}$ & $h_{V}$ & $l_{V}$ \\
\hline 1 & 304.31 & 86.61 & 362.60 & 268.89 & 15.62 & 272.05 \\
2 & 253.21 & 50.29 & 276.06 & 224.42 & 9.56 & 227.48 \\
3 & 289.61 & 67.54 & 326.23 & 281.63 & 13.84 & 284.28 \\
4 & 294.27 & 78.07 & 344.00 & 384.82 & 11.87 & 386.62 \\
5 & 252.29 & 100.68 & 339.62 & 336.58 & 64.84 & 364.48 \\
6 & 290.30 & 53.38 & 314.98 & 320.30 & 13.20 & 323.25 \\
7 & 300.02 & 54.46 & 321.26 & 235.66 & 2.21 & 235.95 \\
8 & 272.49 & 64.53 & 308.42 & 208.23 & 11.49 & 214.94 \\
9 & 276.05 & 58.59 & 307.15 & 337.17 & 25.79 & 342.53 \\
10 & 315.11 & 95.75 & 383.02 & 156.98 & 9.32 & 159.15 \\
11 & 284.08 & 74.35 & 333.88 & 274.25 & 13.14 & 278.51 \\
12 & 348.24 & 82.06 & 412.56 & 252.35 & 46.73 & 273.02 \\
13 & 323.99 & 75.24 & 369.34 & 330.10 & 9.29 & 333.59 \\
14 & 332.15 & 82.27 & 383.46 & 288.23 & 23.58 & 296.57 \\
15 & 229.57 & 66.71 & 283.72 & 318.44 & 47.99 & 340.40 \\
16 & 302.74 & 62.13 & 331.72 & 278.60 & 30.04 & 289.58 \\
17 & 308.40 & 53.23 & 333.17 & 350.68 & 16.55 & 359.00 \\
\hline
\end{tabular}

Table III

DESCRIPTION OF INDIVIDUALS ACCORDING TO THE MORPHOMETRIC PARAMETERS CALCULATED

\section{TOWARDS A TYPOLOGY OF ABDOMINAL MORPHOLOGIES}

After describing individuals in this parameter space, our goal is to automatically extract groups of abdominal morpholo- 


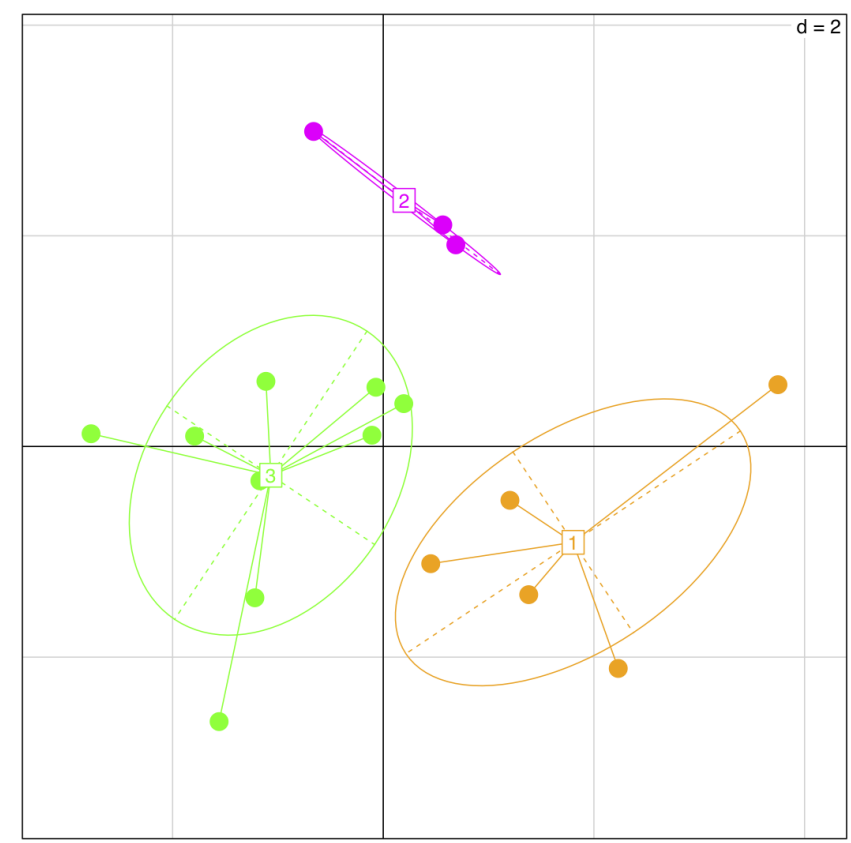

Figure 6. Representation, in the factorial design, of individuals and clusters obtained by the k-medoids algorithm.

gies by clustering.

We first proceed to a principal component analysis to reduce the dimensionality of the problem and to project people in a subspace whose components are uncorrelated. The representation of subjects in the factorial subspace (related to the first two principal components) allows us to visualize the similarities between individuals (Figure 6).

First, clustering is achieved, using the k-medoids algorithm. The algorithm is used in the space of the first 3 factors (consideration of the eigenvalues shows that the first 3 principal components explain $94 \%$ of the inertia) and it is set to search for 3 clusters (after reading the dendrogram obtained by hierarchical clustering).

The statistical description of obtained clusters is presented in the table IV. The medoids produced by the clustering algorithm provide representative individuals of each cluster (Table V). For a more detailed extraction of representative individuals (or exemplars) we can use the method described in [20].

\section{CONCLUSION}

In this paper, we presented a software prototype able to acquire abdominal morphological parameters using a consumer electronics depth sensor. This prototype is lightweight and inexpensive, and the acquisition is quite insensitive to the capture conditions (this type of sensor is designed to operate in most environments, in private homes).

We also proposed an algorithmic solution to analyze collected data. The results presented in this paper allowed us to validate the principle and the calculation methods of our tool. The aim was not to draw medical conclusions but to establish a

\begin{tabular}{rllrrrr}
\hline param. & cluster & mean & sd & median & min & max \\
\hline$d_{H}$ & 1 & 324.76 & 16.72 & 323.99 & 304.31 & 348.24 \\
$d_{H}$ & 2 & 275.24 & 23.53 & 272.49 & 253.21 & 300.02 \\
$d_{H}$ & 3 & 280.81 & 25.16 & 289.61 & 229.57 & 308.40 \\
$h_{H}$ & 1 & 84.39 & 7.55 & 82.27 & 75.24 & 95.75 \\
$h_{H}$ & 2 & 56.43 & 7.32 & 54.46 & 50.29 & 64.53 \\
$h_{H}$ & 3 & 68.30 & 14.86 & 66.71 & 53.23 & 100.68 \\
$l_{H}$ & 1 & 382.20 & 19.19 & 383.02 & 362.60 & 412.56 \\
$l_{H}$ & 2 & 301.91 & 23.29 & 308.42 & 276.06 & 321.26 \\
$l_{H}$ & 3 & 323.83 & 18.97 & 331.72 & 283.72 & 344.00 \\
$d_{V}$ & 1 & 259.31 & 64.15 & 268.89 & 156.98 & 330.10 \\
$d_{V}$ & 2 & 222.77 & 13.79 & 224.42 & 208.23 & 235.66 \\
$d_{V}$ & 3 & 320.27 & 37.07 & 320.30 & 274.25 & 384.82 \\
$h_{V}$ & 1 & 20.91 & 15.58 & 15.62 & 9.29 & 46.73 \\
$h_{V}$ & 2 & 7.75 & 4.89 & 9.56 & 2.21 & 11.49 \\
$h_{V}$ & 3 & 26.36 & 18.62 & 16.55 & 11.87 & 64.84 \\
$l_{V}$ & 1 & 266.88 & 65.20 & 273.02 & 159.15 & 333.59 \\
$l_{V}$ & 2 & 226.12 & 10.57 & 227.48 & 214.94 & 235.95 \\
$l_{V}$ & 3 & 329.85 & 38.60 & 340.40 & 278.51 & 386.62 \\
\hline
\end{tabular}

Table IV

STATISTICAL DESCRIPTION OF CLUSTERS

\begin{tabular}{lrrrrrrr}
\hline Cluster & $i d$ & $d_{H}$ & $h_{H}$ & $l_{H}$ & $d_{V}$ & $h_{V}$ & $l_{V}$ \\
\hline 1 & 14 & 332.15 & 82.27 & 383.46 & 288.23 & 23.58 & 296.57 \\
2 & 8 & 272.49 & 64.53 & 308.42 & 208.23 & 11.49 & 214.94 \\
3 & 16 & 302.74 & 62.13 & 331.72 & 278.60 & 30.04 & 289.58 \\
\hline
\end{tabular}

Table V

MEDOIDS: REPRESENTATIVE INDIVIDUALS OF OBTAINED CLUSTERS (INDIVIDUALS WHOSE IDENTIFIERS ARE 14, 8 AND 16 ARE RESPECTIVELY THE MEDOIDS OF CLUSTERS 1, 2 AND 3)

proof of concept. Our prototype will now be used in a clinical context dealing with obesity and eating behaviors.

The perspectives of this work are multiple. In order to provide medical practitioners the ability to make a diagnosis, we started to combine this tool with the web framework that we developed [21]. It already supports RGB-D cameras and can transmit the skeletons of users to a distant browser. Provided we also stream the acquired profiles and the descriptors extracted from the analysis, the practitioner may remotely have all the information he needs. So far, our system performs various measurements from a single capture. Using 3D scanning techniques [22], we could capture the entire body surface of a subject, either by moving the camera around, like KinectFusion [23], or by combining several sources simultaneously, as is the case with OmniKinect [24]. Finally, the data analysis should be extended to enable the construction of typologies adapted to the studied diseases, and a much larger amount of data.

\section{ACKNOWLEDGEMENTS}

The authors would like to warmly thank the volunteers who helped them test and improve their prototype.

\section{REFERENCES}

[1] "ObÉpi - enquête épidémiologique nationale sur le surpoids et l'obésité," INSERM, Kantar Health, Roche, Tech. Rep., 2012.

[2] J. C. Nitz, S. Kuys, R. Isles, and S. Fu, "Is the Wii Fit" ${ }^{\mathrm{TM}}$ a newgeneration tool for improving balance, health and well-being? A pilot study," Climacteric, vol. 13, no. 5, pp. 487-491, 2010. 
[3] J.-D. Huang, "Kinerehab: a kinect-based system for physical rehabilitation: a pilot study for young adults with motor disabilities," in The proceedings of the 13th international ACM SIGACCESS conference on Computers and accessibility. New York, NY, USA: ACM, 2011, pp. 319-320.

[4] J. Shotton, A. Fitzgibbon, M. Cook, T. Sharp, M. Finocchio, R. Moore, A. Kipman, and A. Blake, "Real-time human pose recognition in parts from single depth images," in IEEE Conference on Computer Vision and Pattern Recognition (CVPR), Jun. 2011, pp. 1297-1304.

[5] A. Weiss, D. Hirshberg, and M. Black, "Home 3D body scans from noisy image and range data," in IEEE International Conference on Computer Vision (ICCV), 2011, pp. 1951-1958.

[6] E. Stone and M. Skubic, "Evaluation of an inexpensive depth camera for passive in-home fall risk assessment," in 5th International Conference on Pervasive Computing Technologies for Healthcare (PervasiveHealth), 2011, pp. 71-77.

[7] Y.-J. Chang, S.-F. Chen, and J.-D. Huang, "A Kinect-based system for physical rehabilitation: A pilot study for young adults with motor disabilities," Research in Developmental Disabilities, vol. 32, no. 6, pp. 2566-2570, 2011

[8] A. Da Gama, T. Chaves, L. Figueiredo, and V. Teichrieb, "Poster: Improving motor rehabilitation process through a natural interaction based system using Kinect sensor," in IEEE Symposium on $3 D$ User Interfaces (3DUI), 2012, pp. 145-146.

[9] T. Dutta, "Evaluation of the Kinect" ${ }^{\mathrm{TM}}$ sensor for 3-D kinematic measurement in the workplace," Applied Ergonomics, vol. 43, no. 4, pp 645-649, 2012.

[10] I. Samejima, K. Maki, S. Kagami, M. Kouchi, and H. Mizoguchi, “A body dimensions estimation method of subject from a few measurement items using KINECT," in IEEE International Conference on Systems, Man, and Cybernetics (SMC), 2012, pp. 3384-3389.

[11] A. Gonzalez, M. Hayashibe, and P. Fraisse, "Estimation of the center of mass with Kinect and Wii balance board," in IEEE/RSJ International Conference on Intelligent Robots and Systems (IROS), 2012, pp. 1023 1028.

[12] C. Velardo and J. Dugelay, "What can computer vision tell you about your weight?" in Proceedings of the 20th European Signal Processing Conference (EUSIPCO), 2012, pp. 1980-1984.

[13] H. Gonzalez-Jorge, B. Riveiro, E. Vazquez-Fernandez, J. MartínezSánchez, and P. Arias, "Metrological evaluation of Microsoft Kinect and Asus Xtion sensors," Measurement, vol. 46, no. 6, pp. 1800-1806, 2013.

[14] A. J. Stunkard, T. Sørensen, and F. Schulsinger, Use of the Danish Adoption Register for the study of obesity and thinness. New York: Raven Press, 1983.

[15] OpenNI ${ }^{\mathrm{TM}}$, “OpenNI framework," 2010. [Online]. Available: http://www.openni.org/

[16] NiTE ${ }^{\mathrm{TM}}$, "NiTE middleware," 2010. [Online]. Available: http://www.primesense.com/

[17] J.-M. Lu and M.-J. J. Wang, "Automated anthropometric data collection using 3d whole body scanners," Expert Systems with Applications, vol. 35, no. 1-2, pp. 407-414, 2008.

[18] C.-Y. Yu, Y.-H. Lo, and W.-K. Chiou, "The 3d scanner for measuring body surface area: a simplified calculation in the chinese adult," Applied Ergonomics, vol. 34, no. 3, pp. 273-278, 2003.

[19] J.-D. Lin, W.-K. Chiou, H.-F. Weng, Y.-H. Tsai, and T.-H. Liu, "Comparison of three-dimensional anthropometric body surface scanning to waist-hip ratio and body mass index in correlation with metabolic risk factors," Journal of Clinical Epidemiology, vol. 55, no. 8, pp. 757-766, 2002.

[20] F. Blanchard, P. Vautrot, H. Akdag, and M. Herbin, "Data representativeness based on fuzzy set theory," Journal of Uncertain Systems, vol. 4, no. 3, pp. 216-228, august 2010.

[21] O. Nocent, S. Chalençon-Piotin, A. Benassarou, M. Jaisson, and L. Lucas, "Toward an immersion platform for the World Wide Web using 3D displays and tracking devices," in 17th International Conference on 3D Web Technology. Los Angeles, California, USA: ACM Press, Aug. 2012, pp. 69-72.

[22] B. Curless and M. Levoy, "A volumetric method for building complex models from range images," in Proceedings of the 23rd annual conference on Computer graphics and interactive techniques. New York, NY, USA: ACM, 1996, pp. 303-312.

[23] S. Izadi, D. Kim, O. Hilliges, D. Molyneaux, R. Newcombe, P. Kohli, J. Shotton, S. Hodges, D. Freeman, A. Davison, and A. Fitzgibbon,
"KinectFusion: real-time 3D reconstruction and interaction using a moving depth camera," in Proceedings of the 24th annual ACM symposium on User interface software and technology. New York, NY, USA: ACM, 2011, pp. 559-568.

[24] B. Kainz, S. Hauswiesner, G. Reitmayr, M. Steinberger, R. Grasset, L. Gruber, E. Veas, D. Kalkofen, H. Seichter, and D. Schmalstieg, "OmniKinect: real-time dense volumetric data acquisition and applications," in Proceedings of the 18th ACM symposium on Virtual reality software and technology. New York, NY, USA: ACM, 2012, pp. 25-32. 